\title{
Approaches to Teaching Marguerite de Navarre's «Heptameron», edited by Colette H. Winn
}

\section{Michele Mastroianni}

\section{(2) OpenEdition}

1 Journals

\section{Edizione digitale}

URL: http://journals.openedition.org/studifrancesi/7872

DOI: $10.4000 /$ studifrancesi.7872

ISSN: 2421-5856

\section{Editore}

Rosenberg \& Sellier

\section{Edizione cartacea}

Data di pubblicazione: 1 juillet 2009

Paginazione: 380-381

ISSN: 0039-2944

\section{Notizia bibliografica digitale}

Michele Mastroianni, «Approaches to Teaching Marguerite de Navarre's «Heptameron», edited by

Colette H. Winn», Studi Francesi [Online], 158 (LIII | II) | 2009, online dal 30 novembre 2015, consultato il

11 janvier 2021. URL: http://journals.openedition.org/studifrancesi/7872 ; DOI: https://doi.org/

10.4000/studifrancesi.7872

\section{Questo documento è stato generato automaticamente il 11 janvier 2021.}

\section{(c) 9 (i) $\Theta$}

Studi Francesi è distribuita con Licenza Creative Commons Attribuzione - Non commerciale - Non opere derivate 4.0 Internazionale. 


\title{
Approaches to Teaching Marguerite de Navarre's "Heptameron», edited by Colette H. Winn
}

\author{
Michele Mastroianni
}

\section{NOTIZIA}

Approaches to Teaching Marguerite de Navarre's «Heptameron», edited by Colette H. WINN, New York, The Modern Language Association of America, 2007, pp. XVI-247.

1 Nella benemerita collana, destinata agli studenti universitari, «Approaches to Teaching World Literature» della MLA segnaliamo il volume consacrato all'Heptameron di Marguerite de Navarre, in quanto, pur nella sua destinazione didattica di «Introduzione», fornisce numerosi e aggiornati contributi da parte di alcuni tra i maggiori cinquecentisti del momento, raccolti nella seconda sezione del volume (Approaches, pp. 29-213), ove ventisette brevi saggi indagano sull'Heptameron, situandolo nel suo contesto storico e culturale, mettendo in luce le ideologie religiose e politiche sottostanti, ritracciando la storia della sua diffusione e fortuna, chiarendo i rapporti con le altre opere di Marguerite. Densi di informazioni, i vari articoli offrono il punto più aggiornato della ricerca, completata da una ricca bibliografia finale. Nella prima sezione del volume (Materials, pp. 3-25) viene fatta una rassegna critica delle edizioni dell'Heptameron, viene offerto un panorama bibliografico ragionato e vengono indicati strumenti didattici di vario tipo (anche audiovisivi e informatici). 